This item was submitted to Loughborough's Research Repository by the author.

Items in Figshare are protected by copyright, with all rights reserved, unless otherwise indicated.

\title{
'Intensive mothering' in the early years: the cultivation and consolidation of (physical) capital
}

PLEASE CITE THE PUBLISHED VERSION

http://dx.doi.org/10.1080/13573322.2014.941797

PUBLISHER

(C) Taylor and Francis

\section{VERSION}

AM (Accepted Manuscript)

\section{PUBLISHER STATEMENT}

This work is made available according to the conditions of the Creative Commons Attribution-NonCommercialNoDerivatives 4.0 International (CC BY-NC-ND 4.0) licence. Full details of this licence are available at: https://creativecommons.org/licenses/by-nc-nd/4.0/

\section{LICENCE}

CC BY-NC-ND 4.0

\section{REPOSITORY RECORD}

Stirrup, Julie, Rebecca Duncombe, and Rachel A. Sandford. 2019. "intensive Mothering' in the Early Years: The Cultivation and Consolidation of (physical) Capital". figshare. https://hdl.handle.net/2134/19794. 
'Intensive Mothering' in the Early Years: the cultivation and consolidation of (physical) capital

Julie Stirrup*, Rebecca Duncombe, Rachel Sandford

Loughborough University,

School of Sport, Exercise and Health Science,

Loughborough

LE11 3TU

01509263171

Corresponding author: j.l.stirrup@lboro.ac.uk* 


\section{Abstract}

Growing pressure on parents to equip their children with the skills required for future success, coupled with an increased focus on providing quality learning experiences in the early years, have contributed to an upsurge in the enrolment of young children in formal (often privatised) activities. Moreover, in response to growing societal concerns over the perceived risks of obesity and sedentary lifestyles, parents are often acutely aware of the importance of providing plentiful physical activity opportunities for their children within this enrichment context. In this paper, the tendency for parents to provide copious developmental opportunities is referred to as 'intensive mothering' and is explored through the theoretical lens of Bourdieu, specifically his concepts of habitus and capital. This paper reports on a small-scale study undertaken within the UK, which sought to explore the impact of social class on access to early years' provision as well as parental attitudes towards physical activity and the provision of preschool physical development opportunities. Data were generated through a questionnaire (disseminated via early years settings) as well as 3 in-depth interviews with 'middle class' parents and were analysed to draw out key themes relating to the cultivation and consolidation of (physical) capital. The data indicate that many parents perceive a 'responsibility' to aid their children's physical development and demonstrate a willingness to facilitate the acquisition of physical capital via the provision of play equipment, privatised classes and additional (informal) physical activity opportunities. Moreover, they suggest that 'middle class' parents, in particular, articulate the need to invest heavily in enrichment activities, influenced by their own experiences, tastes and values. It is argued that 'intensive mothering' is illustrative of the reproduction of a class-based habitus and can be perceived as an attempt to maintain or improve social position through the cultivation, consolidation and, ultimately, conversion, of appropriate capital.

Key words: intensive mothering, early years, physical development, capital and habitus 


\section{Introduction}

Parents in the UK and indeed in other countries (e.g. Australia, New Zealand), are increasingly operating within a market of educational and physical activity services which are no longer simply a matter of choice and competition between publicly funded 'state' provided educational institutions and the different forms of PE and sport which they provide. In these 'new' conditions, the acquisition of corporeal capital is now provided by a combination of transmissions at school, in families and from those 'bought in’ from the market (Evans \& Davies, 2011; Raine, 2007; Pope, 2012; Macdonald, 2012; Macdonald, et al., 2008). Certainly, in the UK as elsewhere (see Mol, 2007; Nairn et. al, 2012), there has been increased momentum toward the privatisation of education at both secondary and primary school level. Moreover, the current coalition Liberal/Conservative (Lib/Con) Government has added considerable impetus to this process, requiring society and individuals to be self-responsible, selfactualising and self-governing (Rizvi and Lingard, 2010). With this in mind, there is a growing recognition that what children achieve in later life, is determined in the early years; in the investments in physical and other forms of cultural capital they receive at home and from early years education (DfE, 2013).

This is all occurring in a culture where there is 'a seething and swarming of official discourse around parenting', exacerbated by a plethora of media and public policy messages intended to convey to parents that they and their offspring face imminent 'risk' (Ball, 2010; 160). Risk in this sense means, not simply being subjected to lowered educational standards and of falling behind in the educational marketplace, but also, increasingly, of falling prey to contemporary health maladies (such as obesity) unless steps are taken (early in life) to counter and guard against them. There are questions to be asked here with regard to equity, however, as access may depend upon the amount of economic capital available to families to exploit the opportunities available. This paper is concerned with exploring some of these issues within the context of early years learning (EYL) and physical development in the UK, using a theoretical lens informed by Bourdieu. In particular, it seeks to examine the opportunities pre-school children (ages 0-5) have to participate in physical activity and, drawing on empirical data, discusses the influence of social class and culture both on parents' opportunities (and dispositions) to invest in this way and their choice 
of physical activity experiences. The paper begins by outlining some of the recent developments within EYL in the UK, before considering the concept of 'intensive mothering' as a means of explaining parents' involvement in the concerted cultivation of capital. The theoretical framework of the paper is then discussed, in particular Bourdieu's central concepts of habitus and capital, before the study itself is outlined. Following a discussion of the methods used and data analysis process undertaken, the final sections of the paper present a discussion of key themes relating to the cultivation and consolidation of (physical) capital by parents and the role that class differences may play in this process.

\section{The Current Landscape of Early Years Learning and Physical Development}

Recent developments within early years learning (EYL) (ages 0-5 years) in the UK have led to an increased focus on the quantity and quality of physical activity provision for young children. The latest UK physical activity guidelines, for example, recommend that young children capable of walking are active for at least 180 minutes a day and that babies and non-walking toddlers are provided with ample opportunity to 'move' (DoH, 2011). Furthermore, the revision of the Early Years Foundation Stage (EYFS) framework in 2012 saw 'Physical Development' promoted to one of three key aims (the others being personal, social and emotional development and communication and language). Within the area of physical development, the prime areas of focus relate to 'Moving and Handling' (referring to children's ability to show good control and co-ordination in small and large movement and to move confidently in a range of ways) and 'Health and Self-Care' (whereby children know the importance of good health, physical exercise and a healthy diet and can talk about ways to keep healthy and safe) again reinforcing the perceived need for physical movement (see DfE, 2012: 8).

Concerns around the lack of appropriate movement opportunities for young children (Goddard-Blythe, 2005) and the impact of poor early years' learning experiences on future education (Sammons, et al., 2004), combined with increasing health concerns focused on obesity and sedentary lifestyles (Marsden and Weston, 2007) have contributed to a growing awareness of the importance of physical activity/development in the early years and a number of programmes (e.g. BUPA 'Start to Move' and 
BHF 'Early Movers ${ }^{1}$ ) have been implemented in an attempt to combat this. Further evidence of this increasing concern can be seen through a number of recent changes in government policy. In 1998, for example, the Labour government introduced the 'Sure Start Children's Centres' in the UK (hereafter referred to as Sure Start). According to policy rhetoric, the core purpose of these centres is to 'improve the outcomes for young children and their families, with particular focus on the most disadvantaged families to reduce inequalities in child development and develop children's school readiness' (DfE, Nov 2011). They are to offer a variety of services to parents, from advice on parenting to health visits and childcare. Essentially for children and parents of children aged 0-5, Sure Start offers a range of activities (often age-based and usually for an hour duration) that parents can access free of charge (e.g. Babbling Babies, Messy Hands, Toy Library) and which often run weekly or monthly. However, despite their initial focus on engaging with those 'hard to reach' parents and children (Pemberton and Mason, 2008), there is growing evidence to suggest that it is the middle classes (rather than those most in need) who tend to utilise these Sure Start facilities the most (Coughlan 2011).

A further example of the growing commitment to early years' learning can be seen through the introduction of government funded places in EYL settings (15 hours per week for 38 weeks a year since 2012) and, prior to this, the Labour government's childcare tax credit system which was designed to encourage mothers back into paid employment. Despite this, however, Penn (2007) identified that, in some instances, the cost of childcare was approximately twenty-eight percent of a household's average disposable income. Clearly, providing 'official' opportunities for early years learning is a costly endeavour and parents are thus faced with something of a dilemma. On the one hand, they are informed of the importance of quality early years learning and physical development experiences, but on the other, the reality is that such experience does not necessarily come without expense. Compounding this situation, there also appears to be a growing societal pressure for parents to expose their young children to a variety of, often privatised, classes and activities in order to supplement their development; a tendency which we, like others, refer to as 'intensive mothering' (see Hays, 1996). This concept is

\footnotetext{
${ }^{1}$ Both programmes provide training and recourse packs to early years learning providers and practitioners to encourage and help them deliver physically active play to children in the setting.
} 
explored within this paper using the theoretical framework of Bourdieu, specifically his concepts of 'habitus' and 'capital' (Bourdieu, 1986) and is discussed in more detail in the following section.

\section{Intensive Mothering: the Cultivation and Consolidation of (Physical) Capital}

Enrichment activities (music, sport and art related activities for young children) have been described as a 'booming' area, with provision and consumption increasing significantly over the last three decades (Vincent \& Ball, 2006). The market place is saturated with franchises offering often expensive (at least $£ 5$ per session) provision for pre-school children, from the well-established 'Tumble Tots’ (a gymnasticsbased physical play programme that has been running since 1979), to more recent activities including 'Water Babies, 'Shakers Music' and 'Jo Jingles'. In light of this 'booming' provision, the parenting styles of the middles classes have been labelled as 'intensive or cultivated parenting' (e.g. Hays, 1996; Laureau, 2003). In the UK, Vincent and Ball (2007) have highlighted that class divisions are clearly visible within the realm of child rearing and they have illustrated how, in an attempt to invest in their children's habitus and capital, middle class parents often enrol their children into such enrichment activities (outside of EYL nursery settings) to develop their talents and abilities.

There is a significant amount of evidence that enrolling under-fives in enrichment activities is now a central aspect of 'good' parenting among certain social groups (Evans \& Davies, 2010; Lareau, 2003; Vincent \& Ball, 2006, 2007). Vincent and Ball (2006; 158), for example, suggest that such enrichment activities serve two purposes; 'forming the beginnings of a curriculum vitae' and enhancing 'learning readiness' - both of which follow the general trend of 'scholarisation of childhood' or, as Evans and Davies (2010) refer to it, the 'corporalisation of childhood' (i.e. the middle classes developing their children's bodily orientations through enrichment activities). There is a focus on moulding and developing their children in particular social and educational directions, e.g., with trips to the museum/theatre or extra academic work set at home, resulting in the home becoming a site of pedagogy (Vincent, 2012). In effect, theirs is an active endorsement of neoliberal subjectivity ${ }^{2}$, with middle class parents assuming responsibility for their (dependent) child's/children's educational, social, cultural and

\footnotetext{
2 There is an increasing influence from government for personal agency and decision making. Children participation in 'extracurricular' activities, resonates with a neoliberal economic and political environment which prioritises individualism and fosters children subjugation through self-governance (Raby, 2014)
} 
physical 'success'. Constant comparison and heightened feelings of guilt are, perhaps, inevitable outcomes of such processes; with parents taking on responsibility for ensuring that their children develop the 'right' skills/abilities at appropriate times. Of course, such guilt by comparison may be equally evident amongst working class parents, if they share such aspirations for their children. However, not having the financial wherewithal to pursue them, their sense of 'guilt' and inadequacy may be seriously heightened. It is worth noting, for example, that the average (middle class) family spends annually over one thousand pounds per child between the ages of six months and eight years on additional classes and activities (Vincent \& Ball, 2007).

This raises some important questions with regard to developmental opportunities in the early years. For example, with physical development thus endorsed in public and policy rhetoric as a key area in children's overall development, we might ask, how does the current EYL landscape accommodate and provide for physical activity? Who can (and does) access such provision? Does it provide EYL opportunities that are 'equitable' and accessible for all? If not, what are the implications for physical development? Adopting a Bourdieuian perspective, this paper looks to explore some of these questions and discusses, in particular, parents' opportunities (and dispositions) to cultivate their children's physical and social capital through facilitating their engagement in appropriate activities.

\section{Theoretical Framework}

The data presented in this paper offers persuasive evidence of 'intensive mothering', realised through a variety of both formal and informal activities provided by the family, state and private enterprise. In particular, we suggest that the concepts 'habitus' and 'capital' are a valuable means of illustrating how parents' practice with regard to their children's physical development can be influenced both by social structures and individual agency (Jenkins, 1992). For Bourdieu, an individual both shapes and is shaped by their engagements with various social fields, their practice being influenced by the expected norms/standards of those fields, their own position within them (relative to others) and the resources (capital) available to them (e.g. Bourdieu, 1985). Moreover, his concept of habitus was developed to explain how, over time, 'the social is written into the corporeal' (Jarvie \& Maguire, 1994) as individuals 
come to learn the style, manner and customs etc., required to 'play the game' and be active members within their own social context. Significantly, habitus, as the embodied history of social practices (Bourdieu, 1990) can be seen to reflect social and cultural distinctions differences (e.g. relating to gender, class, race), which are then, in turn, reflected in and reinforced through, subsequent practice. Some of this difference reflects the unequal distribution of resources (capital) between individuals and groups within fields. Capital can be thought of as representing the particular goods or resources available to individuals within fields, and is conceptualised in various forms e.g. economic, cultural, social and physical. The concept of 'intensive mothering' would seem to resonate with Bourdieu's theory of cultural capital and the embodied state (Bourdieu, 1986). The forms of capital represent the 'stakes at stake' (Bourdieu, 1985) and have the capacity to empower their holder; influencing, in part, an individual's position within the field and their capacity to determine the legitimacy of forms of capital. The great value in the concept of capital, however lies in the capacity for transformation or conversion; that is, the (re)investment of resources in an attempt to create capital with 'exchange value' (Shilling, 1993). Individuals seek to maximise the volume and composition of capital they possess and, through this, strive to improve or consolidate their social position (Green, 2010). Capital, therefore, is implicated in issues of access and the concept of capital has been widely used to explain the unequal achievement of children from different classes and socio economic status within school contexts (Lareau and Weininger, 2003; Reay, 2004; Andersen and Hasen, 2012).

Within this discussion, we argue that the family, parents in particular, represent significant influences on children's accumulation/transfer of capital and that their disposition to seek out opportunities for such 'capital investment' can be seen to reflect, in part, their class-based habitus. Before further discussion on this, however, the following sections will provide an outline of the study design as well as the processes used to generate, collate and analyse the data.

\section{Methodology}

The data presented within this paper were collected through a small-scale research project, conducted as part of a larger, on-going, ethnographic study relating to class, culture and embodiment in three early years settings (Stirrup, forthcoming). The larger study draws on the work of both Bernstein and Bourdieu 
to focus on how social class is enacted through the pedagogical transactions which occur within EYL settings. Exploring what is currently an under-researched area, the study represents an attempt to uncover the subtleties and complexities of social class and cultural (in)equalities within early childhood education and play, with a view to furthering understanding of their impact on children's orientation towards the body, physical activity and health. The work presented here was funded by a small research grant and was intended to explore parental views of physical development/activity, as well as the physical activity opportunities provided (by parents and others) for their young children. In doing so, it was envisioned that the research would generate data that could provide a broader context to enhance the larger study. Before commencement, ethical clearance was obtained from (the authors') university and relevant procedures were followed with regard to attaining consent (from nursery owners/managers and parents) and assuring anonymity/confidentiality.

In the first phase of research (May 2012) a questionnaire ( $\mathrm{n}=60)$ was distributed to parents in three case study EYL settings which formed part of the wider study ${ }^{3}$. The questionnaire was subsequently reviewed, revised and redistributed to a larger number of parents $(n=200)$ across all of the preschool settings in the same local authority; 79 responses were received and these form the bases of this analyses. This redeveloped questionnaire was divided into five sections:

- Demographic information;

- Parental reasons for nursery selection;

- Formal/organised activities that their child attends/has attended (e.g. Tumble Tots);

- Informal activities provided for their children (e.g. walking, trips to the park, cycling);

- Parental attitudes to physical activity.

At the end of the questionnaires, parents were invited to take part in additional research in the form of case study telephone interviews. These were intended to facilitate further investigation of relationships between socio-economic status, parental attitudes towards physical activity and the provision of physical

\footnotetext{
${ }^{3}$ The limited research funding for this small study, in addition to the specific scope of the larger study, meant that the questionnaire looked at nursery settings only; as such, little is known (or can be said) about parents' use of additional EYL settings/contexts (e.g. child-minders etc.), beyond the information offered voluntarily in the interview process. Acknowledging, that this aspect of provision is beyond the scope of this particular study, however, we recognise that research into this area offers a potentially valuable avenue for future research
} 
development opportunities. From the positive responses, several interesting 'cases' of different forms of parental investment in formal and informal activity were identified, and three in-depth interviews were ultimately conducted to illustrate them. The interview schedule was semi-structured in order to ensure key issues were covered, but also to allow for deeper exploration of interesting/unanticipated points of discussion (Patton, 2002; Denscombe, 2007). Questions explored parents’ views on physical activity at and outside of their child's EY setting, as well as the opportunities that they themselves provided for their child. The interviews lasted between 30 and 45 minutes each and were audio-taped before being transcribed. Information regarding the participants involved in the study (both questionnaire respondents and interviewees) is provided below.

\section{Participants}

\section{(a) Questionnaire Respondents}

Of the thirty EYL settings identified within the local authority, twenty eight agreed to participate in this research. Of these, twenty two were privately owned, three were playgroups (two of which are Council/ i.e., local government funded) and three were preschools attached to local primary schools. A total of 79 were returned for analysis from across thirteen sites (of which eleven were privately funded and two publically funded). The majority of families that responded were White British; 72 mothers and 7 fathers completed the questionnaires and, of these, $54 \%$ were completed for a son and $46 \%$ for a daughter. Of the respondents, $82 \%$ of mothers were employed (only 18.2\% full-time) and $94.1 \%$ of fathers were employed. Whilst the proportion of mothers employed full-time is low, respondent comments suggest that this was due to individuals electing to take on childcare responsibilities themselves rather than work full-time (or at all). Parents provided their postcodes, enabling their socio-economic status to be calculated (using the Office for National Statistics indices of deprivation measure). The mean SES score for those who responded was 24,131 (with the lowest score being 2582 and the highest 32,142). According to this measure of socio-economic status, the sample under investigation here could be described as being skewed towards the higher middle class end and this must be acknowledged as a limitation when reading the data. 


\section{(b) Parental Interviewees}

From the follow-up responses received, parental interviews were conducted with three mothers who had been selected as examples of 'middle class' parents and their investments in formal and formal activity. The ONS indices of social deprivation scores implied all were, to varying degrees, living in reasonably affluent areas. The following table (table 1) provides a profile of the interviewees, highlighting the reasons for each mother's choice of child care, their child's engagement in formal classes and the mother's own attitude towards physical activity.

(Insert Table 1 here)

\section{Data Analysis}

The questionnaires were collated and parents' responses entered into an Excel spreadsheet in order to manage the data. Descriptive statistics were generated to facilitate the identification of patterns (e.g. the percentage of parents who felt formal/informal activities were important for their child or proportion of respondents who identified themselves as being 'active') and, thereby, give greater context to the data. The qualitative data (open-ended survey responses and telephone interview transcripts) were analysed using a thematic approach, similar to the constructivist grounded theory approach described by Charmaz (2000). In this respect, the transcripts were read (and re-read) and a process of coding was used to organise, retrieve and associate fragments of data, thereby enabling the identification of key themes (Miles \& Huberman, 1994). It should be noted, however, that the analytical process was also influenced by the theoretical framework adopted for this work with Bourdieu's concepts of habitus and capital (in particular) influencing, in part, the reading of the data and the conceptualisation of theory. While themes 
emerged freely from the parents' data (e.g. the perceived need to provide activity opportunities for their children), the interpretation of these themes was viewed through the lens of Bourdieu (e.g. activity as a means of developing physical capital). The following sections of the paper examine the data generated via the redeveloped questionnaire (both closed and open-answer questions) and three in-depth parent telephone interviews. While the questionnaire data paints a broad picture of young children's engagement with physical activity in the pre-school years, the interview data helps to shed more light on the physical activity opportunities provided for young children and the parental motivations and dispositions behind these.

\section{Findings}

Parental Investment in (Physical) Capital

A distinction was drawn between 'formal' activities, such as activities with set times and locations (e.g. swimming lessons or gymnastics classes) most of which were provided by private providers, and more 'informal' activities, such as going to the park or for a walk. Sixteen different types of formal activities were identified as having been attended, at some point, by children involved in this study (see table 2), with 12 of these being privatised sessions (i.e. fee-paying). Moreover, around $48 \%$ of children were shown to still be attending formal activity sessions.

(Insert Table 2 here)

It was therefore evident that a high percentage of parents sought to provide physical activity opportunities through formal sessions (e.g., swimming, dance, gymnastics, tennis, and rugby, martial arts and music and movement class). Most parents indicated their desire to seek out opportunities that facilitated the generation of relevant academic capital, i.e., they sought environments that provided ‘positive learning opportunities'. 'Other’ reasons given included, improving confidence; providing positive social experiences (for children and parents); and presenting opportunities for children to be 
active or exercised. However, the data also revealed that parents provided numerous opportunities for their children to engage in informal physical activities (e.g. general walking, playing in the garden and using a bicycle or scooter) with $67 \%$ feeling it was important for their child to participate in both informal and formal types of activities. Evidently the 'middle class' parents of this sample were eager to 'enrich their children' with physical and social capital both formally and informally inside and outside the home.

\section{Social Class Influences on Young Children's Physical Activity}

As noted earlier, we need to bear in mind that parents who responded to the questionnaire were largely 'middle class' and, as such, we can only speculate as to how behaviours reported here compare with those of working class parents and children. Moreover, the numbers reported in table 3 and 4 are small and thus do not lend themselves to unqualified generalisation. However, they are clearly indicative of processes that Wheeler (2013), among others, have revealed elsewhere. Green (2010) too has provided evidence of parents transmitting cultural capital to their children, with researchers finding similar sporting tastes, skills and abilities within families. Furthermore, Green, Smith and Roberts, (2005) claim that middle class parents are not only more likely to have the economic capital but are also more able to transfer their social and cultural capital because it is more likely they are involved in sports/physical activity themselves.

(Insert Table 3 and 4 here)

These figures suggest that while children from all social backgrounds have opportunities to engage with formal physical activities, the children of middle class parents (and indeed those who live in areas of lower social deprivation) are more likely to have sustained involvement with such activities. As such, they enjoy greater opportunities to cultivate and consolidate social and physical capital. 
If nothing more, the aforementioned data highlights the important contribution that both formal and informal activities can make to a young child's physical activity and, potentially, to their physical development within the early years. Questionnaire data alone, however, cannot determine whether such views are underpinned by a conscious belief that engaging in physical activities can help maximise the amount of capital young children are able to accumulate, or whether the search for and provision of physical activity opportunities for their children represent conscious efforts on the part of parents to meet social norms/requirements regarding young people’s health. The data are merely suggestive of such processes. They indicate that most parents were influenced by social and media discourses around health and fitness, acknowledging, for example, the importance of physical activity for health. However, there is little specific data to indicate that such discourses consciously informed the specific choices they made regarding physical activity provision for their children. The in-depth parent interviews, on the other hand, do shed light on these issues and provide further insight into how class-influenced dispositions inform and underpin parents' attitudes towards their children’s physical development.

\section{The Transmission of Physical Activity Values}

All three mothers interviewed acknowledged that they had enjoyed participating in sport and physical activity when they were younger and had participated in various structured activities (dance, swimming, hockey, cross-country etc.) inside and/or outside of school. Moreover, there was an acknowledgement that this participation was influenced by their own (middle class) family histories (with parents and siblings also cited as being active) and played a role in shaping their own attitudes as parents. For example:

"My father played sport, squash, tennis, racket sports, that kind of thing, (and) our weekends would often involve swimming and a walk, an adventure, you know. Lily and I, we do that now...I think you're trying to show, aren't you, that if you do it as a child then you pass it on" (Claire).

"I think that I have always been active, and always enjoyed being active, and I want Charlie to be active to and enjoy the things that I did" (Jennifer). 
"I think we both see activity as being important and hope that Charlie will grow up with this in mind too" (Jennifer).

"We used to go and play rounders and cricket, like I say we used to go up the university and play tennis and go swimming” (Lyn).

These parents' disposition to be active and to see the value in their children being physically active appears to stem from their specific childhood experiences. Over time, these experiences have cultivated a particular habitus, which is now being reinforced and reproduced through their actions as parents. In effect, there is a transmission of values relating to physical activity and social norms/ideals regarding healthy behaviour.

“We are pretty healthy (as a family) anyway, so (Charlie) will learn that from us...Neither myself nor my husband are overweight and we would like Charlie to grow up and be a healthy weight too" (Jennifer).

Nursery as a Potential Site to Develop (Physical) Capital

For all of the parents, nursery settings were perceived as means of aiding their child's development (socially, physically and emotionally), facilitating their acquisition of key skills (riding a tricycle, holding a pen, playing with peers) and reinforcing the education provided by parents themselves. In short, they were considered places in which children accumulate and then consolidate their capital. For some parents, this was important in terms of preparing children for school, where having relevant capital in the form of 'academic' skills (e.g. being able to write your name) and knowledge (e.g. about appropriate behaviour etc.) can ease their transition and ensure they more easily meet the requirements of the field. As Lyn noted:

"I wanted Beth to get used to being around other children, get used to the disciplines that are in school and really gain social skills...it just got her a bit of discipline into how they work, sit down on the carpet, do the register, just get her ready for school".

Although there was also was a general acknowledgement amongst these mothers that facilitating their child's development (and, thereby, their acquisition of relevant/valued capital) was a key parental 
responsibility: "Every parent wants their child to be happy and healthy, obviously" (Jennifer). For some, there was also a perception that parents held a particular responsibility with regard to physical development: "With the physical development...I took that as my responsibility” (Claire); "It’s my job, not (the nursery’s)” (Jennifer). Furthermore, all mothers noted that they made a concerted effort to enhance their child's physical development through encouraging the development of basic skills (kicking, catching, throwing etc.). In relation to this, for example, Jennifer noted: "Yes, I try to do these things with him as much as I can, and my husband does too when he’s at home”. This investment can be perceived as an effort to increase their children's physical capital. Moreover, there is an understanding that this can be converted into social capital within other contexts:

"I just think (gymnastics is) a good activity for him and will help him in other areas" (Jennifer).

\section{Provision of opportunities to enhance physical development}

There was a recognition among the parents interviewed, that their relative wealth (as middle class families) allowed them to invest in their children’s physical development (indeed, Jennifer and Claire all refer to themselves as being "lucky") and there were various comments relating to the types of resources they made available:

'(In the garden) Lily's got a pirate ship that's a sandpit which she loves and it's got pulleys and levers... she's got a couple of houses, she's got a slide and a swing and a rocket ship and a trampoline...she's got every kind of bike and scooter and pushy thing' (Claire).

“(Beth's) got a trampoline, she’s got a playhouse, big space hopper, she's got roller skates, bowls and skittles, skipping rope, she's got a bike, she's got baby things, like a push along thing (and) a sit and ride thing” (Lyn).

There was also a suggestion that parents sought out opportunities that were suited to their particular child, in other words, those that offered the best chance for accumulating capital. For example:

"Charlie struggles with games like football and team sports, so we tend not to take him to these activities. It's why we have taken him to gymnastics. He loves it and is able to achieve" (Jennifer). 


\section{Discussion}

The above data provide insight into the physical activity experiences of some young children in early year's settings and help to shed light on how and why parents seek to provide such opportunities for their offspring. While not conclusive, they are strongly suggestive of connections between social class and the provision of physical activity; influenced, perhaps, by the relatively skewed sample of respondents. As noted, most parents who responded to the questionnaire were female and from higher SES families. Moreover, where data was collected from parents with low SES, the questionnaire responses provide little detail with regard to the individual opinions and perspectives of parents. As such, we can only speculate as to how the actions and motivations reported here differ from those of working class and ethnic minority parents, both significantly underrepresented in the study (whether due to their underrepresentation in nursery provision or simply because they did not/were unable to return questionnaires).

Notwithstanding these limitations, the data generated do lend strong support for the notion (see Vincent and Ball, 2007) that middle class parents actively seek to provide opportunities for their children to engage with activities in order to enhance their learning and development as investments in social capital. It is evident that, on the whole, parents perceive the need for young children to be given opportunities to engage with both formal and informal activities. Privatised physical education/activity opportunities were routinely part of the landscape for young children within this study, but they were by no means the only experiences on offer. Informal activities made up a greater proportion of the children's physical activity time than structured sessions, and parents often viewed both formal and informal activities as being central to a balanced programme of activity for their children. Although there were, as noted, no clear class distinctions within the data, there was some indication that children living in areas of greater affluence have more opportunities (in terms of time, money and access to transport) to engage in a range of formal activities. Moreover, these young people are more likely than their peers living in areas of higher social deprivation to maintain involvement in such activities. Clearly, there are issues to consider here (not least the cost of activities, the timing of activities and the capacity of parents to take their children to such sessions) which will influence who is able to access these formal activities, but also 
questions regarding the priorities that parents attach to them (see Vincent et al 2010b). Is the above data indicative of intensive middle class mothering? It is perhaps difficult to say authoritatively, but these data point toward the importance placed on enrichment activities in all these young peoples' lives. Moreover, given that privatised activities do play a significant role within this, there are, again, important questions raised around cost and access. On average, the cost per fee-paying activity is approximately $£ 4.50$, although more sports-specific activities (e.g. Socatots, Teddy Tennis) often involve large joining fees (£20-£40) while one swimming programme cited by a parent in this study can cost up to $£ 15$ per session. Formal physical activity can therefore become a costly endeavour, particularly if children have siblings. We may then again ask, with such high costs attached to these enrichment activities, why do parents not make more use of low-cost alternatives available through the voluntary sector (e.g. church affiliated playgroups)? As noted, this research was bounded by the focus on formal EYL contexts in the larger study and did not extend to the use of informal provision by parents. However, our data, in line with previous research (e.g. Talbot, 2013), does offer some suggestions as to why voluntary sector usage might be low. Many of our respondent mothers opted to look after their children full-time and this, coupled with government-funded childcare places from the age of 3 (or 2 years for disadvantaged parents) could explain the low incidence of parental reference to utilising child-minders and low-cost playgroups ${ }^{4}$. Interestingly, the data shows an apparent disconnection between most parents' level of and attitudes towards physical activity and the physical activity provision they make for their children (i.e., most have a positive attitude toward physical activity, but don’t necessarily display high levels of physical activity themselves, although they routinely provide opportunities for children). However, parents who demonstrated the most positive attitude towards physical activity were slightly more likely to offer physical activity opportunities to their children and maintain these over time. This disconnection is perhaps unexpected. Our readings of the data, and subsequent conversations in nursery settings, have suggested that physical activity was not high on all parents' lists of priorities for themselves. For example, while most parents had positive attitudes to physical activity and generally acknowledged the importance of activity for their children, the majority also noted that they exercise two or fewer times a week (again, bearing in mind the physical demands of child care, this is not unsurprising).

\footnotetext{
${ }^{4}$ Previous research (Talbot 2013) suggests that the use of such playgroups is more commonly inhabited by children under three and furthermore that these too often express divisions of social class, gender, ethnicity and geographical location/familiarity.
} 


\section{Conclusion}

It is evidently the case that some children in the early years' experience 'intensive mothering' (Hays, 1996; Lareau, 2003; Vincent and Ball, 2006; 2007; Vincent et al 2010a) and are subjected to a large variety of structured activity sessions outside of nursery. The majority, however, enjoy a more modest variety of public and privately provided activities, but are none the less routinely physically active during the week. The interview data highlights a conscious effort on the part of parents to ensure that the 'right' choices are made in order to give the best possible opportunities to his/her child and allow him/her to acquire the relevant (physical) capital that can be converted (in the right contexts) into social and cultural capital (Shilling, 1994). There is also an acknowledgement that the middle class status of the family facilitates access to a range of resources and opportunities and, moreover, underpins a philosophy of active involvement (embodied in the habitus) in a child's education/development and influences attitudes towards physical development. The interview data brings to light the conscious effort on the part of parents such as Claire to ensure that the 'right' choices are made in order to give the best possible opportunities to her child and allow her to acquire the relevant (physical) capital that can be converted (in the right contexts) into social and cultural capital (Shilling, 1993). There is also an acknowledgement that the middle class status of the family facilitates access to a range of resources and opportunities and, moreover, underpins a philosophy of active involvement (embodied in the habitus) in a child's education/development and influences attitudes towards physical development.

'Intensive mothering' of the middle classes therefore, requires the cultivation and consolidation of capital, which requires a commitment of time and money from parents, which not all can afford. Acknowledging that families strongly influence the development of young children (Dufur, Parcel, Troutman, 2012) if schools exercise more influence as children mature, then physical capital derived from the kind of combination of home/family, private and state/public provisions evidenced in this study, may become critical; not only in terms of advantaging children in EYL settings but also in later school life, setting them apart from others who haven’t been so resourced. Therefore, in an increasingly EYL privatised education system, which offers critical resources for sections of the population (i.e. middle class parents) to maintain their position in the 'privatised' education market and in wider social and 
cultural hierarchies, questions need to be asked regarding what happens to those children whose parents are unable to buy into these resources. 


\section{References}

Andersen, P., and Hansen, M., (2012) Class and Cultural Capital - The Case of Class Inequality in Educational Performance, European Sociological Review 28, 5: 607-621

Ball, S., (2010) New class inequalities in education: why education policy may be looking in the wrong place! Education policy, civil society and social class. International Journal of Sociology and Social Policy, 30: 3/4,155-166

Birth to Three Matters (2005)

http://webarchive.nationalarchives.gov.uk/20130401151715/https://www.education.gov.uk/publica tions/standard/publicationDetail/Page1/Birth\#downloadableparts accessed Nov 2012

Bourdieu, P. (1985). The Genesis of the Concepts of Habitus and of Field. Sociocriticism, Theories and Perspectives, 2(2), 11-24.

Bourdieu, P. (1990a) In other words: essays towards a reflexive sociology. Cambridge: Polity.

Bourdieu, P. (1990b) The Logic of Practice. Cambridge: Polity Press.

Bourdieu, P. (1993) Sociology in Question. London: Sage

Charmaz, K. (2000). Grounded Theory: Objectivist and Subjectivist Methods. In N. K. Denzin \& Y. S. Lincoln (Eds.), Handbook of Qualitative Research (2nd ed., pp. 509-535). Thousand Oaks, $\quad$ CA: Sage Publications.

Coughlan, S., (2011), Childcare: Mothers 'fear playgroup cliques, BBC News, Education Sections: 24th November

DoH (2011) Start Active, Stay Active: A report on physical activity for health from the four home countries'. London: Department of Health.

Denscombe, M., (2007) The Good Research Guide: For Small-scale Social Research (3rd ed) Buckingham: Open University Press

DfE (2011) Supporting families in the foundation years. Available at: www.education.gov.uk/childrenandyoungpeople/earlylearningandchildcare/early/b0077836/introd uction article updated 18th Nov 2011, (accessed Nov 2011)

DfE (2012) Statutory Framework for the Early Years Foundation Stage 2012. Available at: www.webarchive.nationalarchives.gov.uk/20130401151715/https://www.education.gov.uk/publica tions/standard/allpublications/page1/dfe-00023-2012 
Dufur, M., Parcel, T., \& Troutman. K., (2012) Does capital at home matter more than capital at school? Social capital effects on academic achievement. Research in Social Stratification and Mobility.

Early Years Foundation Stage/Curriculum (2012) http://webarchive.nationalarchives.gov.uk/20130401151715/https://www.education.gov.uk/publica tions/standard/publicationDetail/Page1/DCSF-00261-2008 accessed Nov 2012

Evans, J., \& Davies, B. (2010). Family, class and embodiment: Why school physical education makes so little difference to post-school participation patterns in physical activity. International Journal of Qualitative Studies in Education, 23: 7 765-784.

Evans, J., \& Davies, B., (2011) New directions, new questions? Social theory, education and embodiment. Sport, Education and Society, 16:3 263-278

Goddard Blythe, S. (2005) The Well Balanced Child: Movement and Early Learning. Gloucester: Hawthorn Press.

Green, K., (2010), Key themes in youth sport. London: Routledge

Hays, S., (1996) The cultural contradictions of motherhood. New Haven, CT: Yale University Press. Jarvie, G., \& Maguire, J. (1994). Sport and Leisure in Social Thought. London: Routledge.

Jenkins, R. (1992). Pierre Bourdieu. London: Routledge.

Lareau, A., (2003) Unequal childhoods: class, race and family life. Berkeley: University of California Press

Lareau, A., and Weininger, E., (2003) Cultural capital in educational research: A critical assessment. Theory and Society 32: 567-606

Macdonald, D., Hay, P. and Williams, B. (2008). Should you buy? Neo-liberalism, neo-HPE, and your neo-job. New Zealand Physical Educator, 41: 6-13.

Marsden, E., and Weston, C., (2007) Locating quality physical education in early years pedagogy, Sport, Education and Society, 12:4, 383-398.

Miles, M. B., \& Huberman, A. M. (1994). Qualitative Data Analysis: An Expanded Sourcebook (2nd ed.). Thousand Oaks, CA: Sage Publications.

Mol, M. J. (2007). Outsourcing: Design, process, and performance, Cambridge: Cambridge University Press. 
Nairn, K., J. Higgins, \& J. Sligo (2012). Children of Rogernomics. A Neoliberal Generation Leaves School. Otago: Otago University Press.

Patton, M., (2002) Qualitative Research and Evaluation Methods (3rd ed). London: Sage Publications.

Penn, H., (2007). Childcare Market Management: how the United Kingdom Government has reshaped its role in developing early childhood education and care. Contemporary Issues in Early Childhood, 8(3): 192-207

Pemberton, S., and Mason, J., (2009). Co-production and Sure Start Children's Centres: Reflecting upon Users', Perspectives and Implications for Service Delivery, Planning and Evaluation. Social Policy and Society, 8: 13-24

Raby, R. (2014) Children's participation as Neo-Liberal Governance? Discourse: Studies in the Cultural Politics of Education, 35(1), 77-89.

Reay, D. (2004). 'It's all becoming a habitus': Beyond the habitual use of habitus in educational research. British Journal of Sociology of Education, 25(4), 431-444.

Rizvi, F. \& Lingard, B. (2010) Globalizing Education Policy. London: Routledge.

Sammons, P., Elliot, K. Sylva, K, Melhuish, E., Siraj-Blatchford, I. \& Taggart, B. (2004) The impact of pre-school on young children's cognitive attainments at entry to reception, British Educational Research Journal, 30:5, 691-712.

Shilling, C. (1993). The Body and Social Theory. London: Sage Publications.

Stirrup, J ( forthcoming Unpublished PhD Thesis) Early Years Learning (EYL) and Children's orientation towards the Body, Physical Activity and Health, School of Sport, Exercise and health Sciences, Loughborough University.

Vincent, C. \& Ball, S. (2006) Childcare, choice and class practices, London, Routledge

Vincent, C., \& Ball, S., (2007) ‘Making up’ the middle-class child: Families, activities and class dispositions. Sociology 41(6): 1061-77

Vincent, C., Braun, A., \& Ball, S., (2010 a) Between the estate and the state: struggling to be a 'good' mother, British Journal of Sociology of Education, 31 (2): 123-138

Vincent, C., Braun, A., \& Ball, S., (2010 b) Local links, local knowledge: choosing care settings and schools, British Educational Research Journal, 36 (2): 279-298 
Vincent, C., (2006) Childcare Choice and Class Practices: middle class parents and their children. London: Routledge.

Vincent, C., (2012), Parenting; Responsibilities, risks and respect. An Inaugural professional lecture, Institute of Education, University of London, February 2012 